\title{
A Desobstrução Venosa Melhora a Qualidade de Vida?
}

\author{
Calógero Presti. ${ }^{1}$ \\ ${ }^{1}$ SBACV - Sao Paulo - SP \\ E-mail: lopresti@terra.com.br
}

Presti, C. 2013. A Desobstrução Venosa Melhora a Qualidade de Vida?, p.43. In: Bastos, Francisco Reis. Anais do V Simpósio Internacional de Flebologia [Blucher Medical Proceedings n.1 v.1]. São Paulo: Blucher, 2014 http://dx.doi.org/10.5151/medpro-flebo-SIF_23

\section{Resumo}

Objetivo desta apresentação é discutir de maneira crítica as evidências clínicas de melhora da qualidade de vida nos pacientes com trombose venosa profunda aguda (TVP) dos membros inferiores submetidos à desobstrução venosa em relação aos pacientes tratados com anticoagulantes somente.

Há poucos trabalhos na literatura que estudam a história da evolução natural da TVP e a incidência da síndrome pós-trombótica (SPT). Um trabalho prospectivo com 10 anos de seguimento de pacientes com TVP submetido a tratamento com anticoagulantes (Janssen e col. 1997), mostrou que a SPT com sintomas moderados incide em $31 \%$ dos pacientes e com sintomas severos em $2 \%$.

Diante disso, torna-se necessário identificar o paciente que irá se beneficiar com a indicação dos mesmos.

Segundo Delis e col. (2004) os pacientes com TVP ilíacofemoral extensa têm maior incidência de SPT e formas mais graves e mais de metade dos pacientes apresentam claudicação venosa restritiva após 10 anos de acompanhamento.

Na década de 90 trabalhos de grupos escandinavos mostraram excelentes resultados com a trombectomia cirúrgica na prevenção da SPT (Plate e col.1997), no entanto esses resultados nunca foram repetidos por muitos outros serviços em todo o mundo.

Apesar de muitos trabalhos com uso de fibrinolíticos por via sistêmica terem demonstrado que há um grande benefício na prevenção da SPT a sua aplicação tornou-se inviável devido principalmente aos riscos de hemorragia grave. A fibrinólise cateter-dirigida com a utilização de doses muito menores de fibrinolíticos mostrou-se bastante eficaz e com resultados bastante animadores (Comerota e col. 2007).

No entanto as evidências científicas que sustentam a remoção dos trombos na fase aguda são de baixa qualidade. Os estudos multicêntricos randomizados não são consistentes devido à heterogenicidade dos pacientes e muitos apenas reportam os resultados técnicos imediatos (Meissner e col. 2012). 


\section{Conclusão}

Estudos de metanálise comparando a anticoagulação convencional sugerem benefícios na redução de na incidências da SPT. O sucesso da aplicação depende da seleção adequada da técnica e da seleção cuidadosa dos pacientes. Os benefícios na qualidade de vida e o custo-benefício das técnicas necessitam ser melhor avaliados.

Palavras-chave: TUP, insuficiência venosa crônica, desobstrução venosa, varizes, fibrinólise. 